\title{
Compact Multiband Planar Fractal Cantor Antenna for Wireless Applications: An Approach
}

\author{
Gopalakrishnan Srivatsun and Sundaresan Subha Rani \\ Department of Electronics and Communication Engineering, PSG College of Technology, Tamil Nadu, Coimbatore 641004, India \\ Correspondence should be addressed to Gopalakrishnan Srivatsun, srivatsunece@yahoo.co.in
}

Received 16 February 2012; Accepted 20 May 2012

Academic Editor: Dalia N. Elshiekh

Copyright ( $) 2012$ G. Srivatsun and S. Subha Rani. This is an open access article distributed under the Creative Commons Attribution License, which permits unrestricted use, distribution, and reproduction in any medium, provided the original work is properly cited.

A compact multiband fractal antenna which is a new criterion in communication is proposed. The optimized prototype measures $35 \mathrm{~mm} \times 31 \mathrm{~mm} \times 1.6 \mathrm{~mm}$. The proposed antenna covers WLAN IEEE 802.11b, 802.15, PCS, GSM lower and higher bands, DCS, IMT, UMTS, Wi-Fi, and WLAN wireless applications. The proposed antenna exhibits multiband characteristics with an $S_{11}$ of $-30.69 \mathrm{~dB}$ at design frequency and it is found that $\sim 70 \%$ of the $S_{11}$ graph below $-10 \mathrm{~dB}$ reference is achieved. Experimental $S_{11}$ has been compared with the one which is obtained using method of moments. The aim of implementing self-affine fractal concept in antenna design makes it flexible in controlling the resonance and bandwidth. This paper investigates self-affine fractal geometry to miniaturize and to resonate multiband frequencies. The prototype model with a good agreement of $S_{11}$ is reported.

\section{Introduction}

The immense increase in wireless devices and systems to establish wireless connectivity, results in congested wireless band. Wireless market needs a low profile and compact antenna to fit the wireless devices with multiband characteristics. Currently, developed compact broadband antennas are designed for mobile devices [1-10] which involve tuning of non planar, metallic strips and photolithographic concepts partially. This was a motivation to develop a compact multiband antenna, which is essential for wireless applications to solve the needs. The prototype tends to fit IEEE 802.11 series, WLAN, GSM, Wi-Fi, PCS, and DCS frequencies. Microstrip antenna is capable of providing narrowband width, to resonate for multiband, fractal geometry is preferred, and it also occupies less space on wireless boards.

Mandelbrot found the name "fractals" to all that is occurring in nature. Fractal dimensions were not whole numbers, regular, and irregular structures seen in nature [11-23], and latter, John Gianvittoria and many others have devoted to this geometry in particular. A few examples of these geometries are coastlines, mountains, snow structure, fern leaves, bark of trees, and pebbles. Fractal geometry finds a variety of application in engineering and nonengineering fields.

This paper aims at regular self-affine cantor. The visual examinations of self-affine cantor are same in all successive iterations and portray the self-affinity property. As the fractal iteration increases, then the volume of the initiator reduces by $45 \%$ in size, thereby maintaining a radiation pattern compared to that of a normal patch [23]. A self-affine [12] cantor length $(L)$ and the width $(W)$ are reduced to a maximum number of possible iterations $(n)$, through iterative coefficients to shrink the volume of the geometry through which individuality is maintained. This approach provides flexibility in designing a miniaturized antenna. The antenna exhibits multiband resonance by selecting proper scaling factor and optimization of the feed position. Sinha and Jain [24] examined self-affine property of fractals and evaluated the multiband characteristics and implemented the microstrip feed line on a RT-Duroid substrate, and the antenna is found to have finite ground plane of length $85 \mathrm{~mm} \times 85 \mathrm{~mm}$ with aperture coupling to cover the frequency bands at $2.5 \mathrm{GHz}, 5 \mathrm{GHz}$, and $10 \mathrm{GHz}$ with $130 \mathrm{MHz}$, $580 \mathrm{MHz}$, and $690 \mathrm{MHz}$ bandwidths. The above bandwidth is achieved through $3 \mathrm{~mm}$ between the substrate and the 
ground plane. Also, the cost of RT-Duroid is too high when compared to FR4 substrate. [25] Xiaoxiang He designed a dual band antenna for WLAN applications of $109.03 \mathrm{~mm} \times$ $77.88 \mathrm{~mm} \times 102.8 \mathrm{~mm}$ with three parts namely monopole which is in the shape of a fork, rectangular slot and patch. All the three parameters vary and the gain is achieved by adjusting the length and gap using reflector. [26] Liu et al. designed a triple frequency meander monopole antenna on one side and three parasitic strips 1,2 and 3 on the other side measures of $35 \mathrm{~mm} \times 31 \mathrm{~mm}$.

The antenna is etched on a RT Duroid substrate at $2.45 \mathrm{GHz}[27]$ and the antenna that is designed measures $18 \mathrm{~mm} \times 7.2 \mathrm{~mm} \times 0.254 \mathrm{~mm}$. But the antenna is tuned for GPS, DCS-1800, IMT-2000 and WLAN handsets by varying the "s" strip and the height. [28] designed a three band planar antenna covering GSM and Wi-Fi frequency bands along with Sierpinski and meander slits on Arlon substrate. The compact dual band antenna [29] designed for DCS application measuring $30 \mathrm{~mm} \times 30 \mathrm{~mm}$ with both the layers of the substrate with CPW feed is reported in the literature. Hence, a self-affine structure with fractal geometry has been proposed to avoid such complications in designing and tuning to fulfill a variety of wireless applications with a low cost FR4 substrate.

\section{Proposed Design Methodologies}

2.1. Proposed Self-Affine Technique. The proposed self-affine cantor is a rectangle and is called an initiator S1 shown in Figure 1(a). Based on iterative function (IF), the initiator S1 is scaled at center by a factor of two along its length and width of equal dimension, which leads to four rectangles. The topmost corner region is removed thereby retaining the remaining regions as shown in Figure 1(b). Initially, S1 is made to resonate at design frequency by selecting coaxial feed technique. This process is a repetitive procedure and is continued up to $n$th iteration. Iterative function (IF) for selfaffine set is described using (1) and the corresponding values are shown in Figure 2.

2.2. Antenna Design Procedure. The self-affine antenna is developed on a FR4 substrate whose thickness is $1.6 \mathrm{~mm}$, $\varepsilon_{r}=4.4$, and $\tan \delta=0.01$ with ground plane at the bottom. The initiator (S1) measures $38.6 \mathrm{~mm} \times 28.75 \mathrm{~mm} \times 1.6 \mathrm{~mm}$ which resonates near $2.4 \mathrm{GHz}$. Then, $\mathrm{S} 1$ is iterated to obtain (S2) up to (S4) as guided by iterative function, in order to achieve multiband characteristics and the optimized size as shown in Figures 2(a) and 2(b). The set and subsets are assumed in anticlockwise direction for convenience. follows:

The iterative function (IF) of the antenna is derived as

$w(X)$ is a set which is spanned by

$$
\begin{gathered}
w\left\{X_{1}, X_{2}, \ldots, X_{n}\right\}, \quad n=4, \\
w\left(X_{1}\right)=w\left\{X_{11}, \ldots, X_{1 n}\right\} \text { is a subset of } w\left(X_{1}\right) .
\end{gathered}
$$

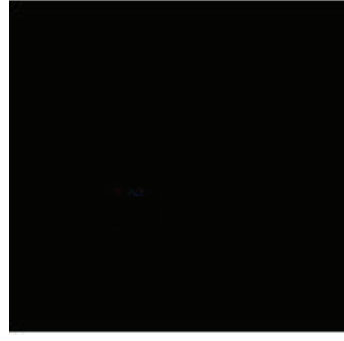

W

(a)

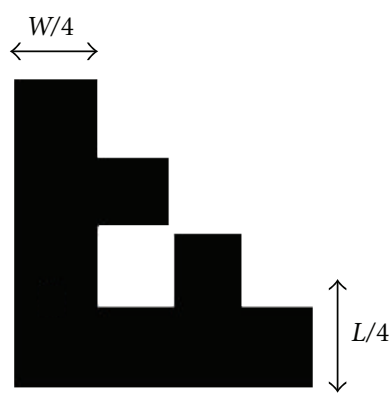

(c)

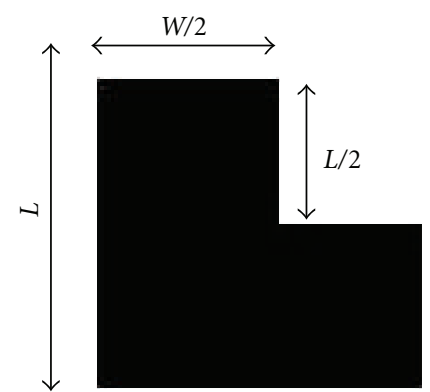

(b)

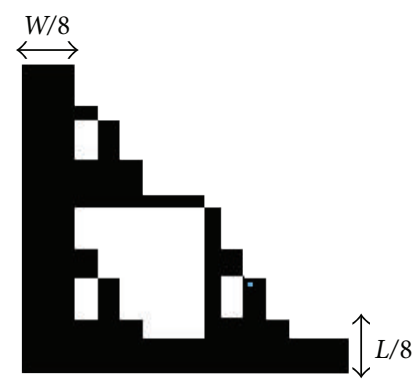

(d)
Figure 1: Self-affine fractal structure. (a) initiator S1; (b) first iteration S2; (c) second iteration S3; (d) third iteration S4.

Equation (2) holds true for remaining subsets $w\left(X_{22}, \ldots\right.$, $\left.X_{2 n}\right)$

$$
\begin{gathered}
w(X)=\bigcup_{i=1}^{4} X_{i} \\
w\left(X_{1}\right)=\bigcup_{i=1}^{4} X_{i}-X_{3},
\end{gathered}
$$

Repetition holds true $\forall$ values of $X_{1}, \ldots, X_{n}$ (except) $X_{3}$,

$$
\begin{gathered}
w\left(X_{2}\right)=\left[\left(\frac{x}{2}, 0\right)(x, 0)\left(x, \frac{y}{2}\right)\left(\frac{x}{2}, \frac{y}{2}\right)\right] \\
w\left(X_{4}\right)=\left[\left(0, \frac{y}{2}\right)\left(\frac{x}{2}, \frac{y}{2}\right)\left(\frac{x}{2}, y\right)(0, y)\right] \\
w\left(X_{11}\right)=\left[(0,0)\left(\frac{x}{4}, 0\right)\left(\frac{x}{4}, \frac{y}{4}\right)\left(0, \frac{y}{4}\right)\right] \\
w\left(X_{12}\right)=\left[\left(\frac{x}{4}, 0\right)\left(\frac{x}{2}, 0\right)\left(\frac{x}{2}, \frac{y}{4}\right)\left(\frac{y}{4}, \frac{y}{4}\right)\right] \\
w\left(X_{41}\right)=\left[\left(0, \frac{y}{4} 0\right)\left(\frac{x}{4}, \frac{y}{4}\right)\left(\frac{x}{4}, \frac{y}{2}\right)\left(0, \frac{y}{2}\right)\right] .
\end{gathered}
$$

Similarly the process can be repeated. But, total volume reduces compared to the original size. The performance of the antenna at different iteration has been investigated using advanced design systems momentum.

The performance for coaxial feed of the self-affine cantor is plotted against frequency and $S_{11}$ is shown in Figures 3, 4 and 5 and the corresponding values are tabulated in Table 1. 


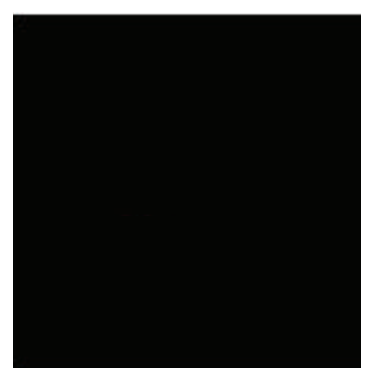

(a)

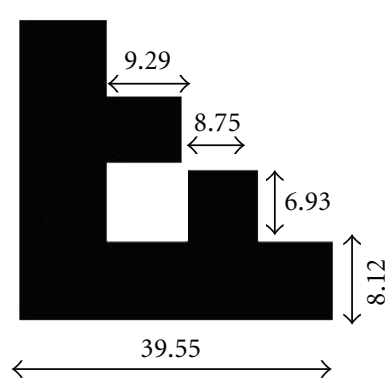

(c)

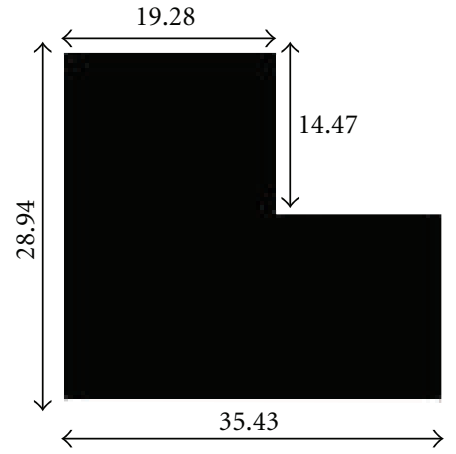

(b)

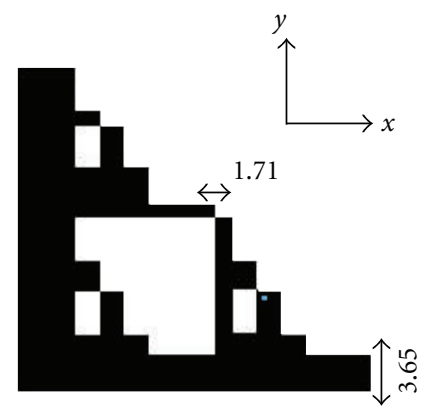

(d)

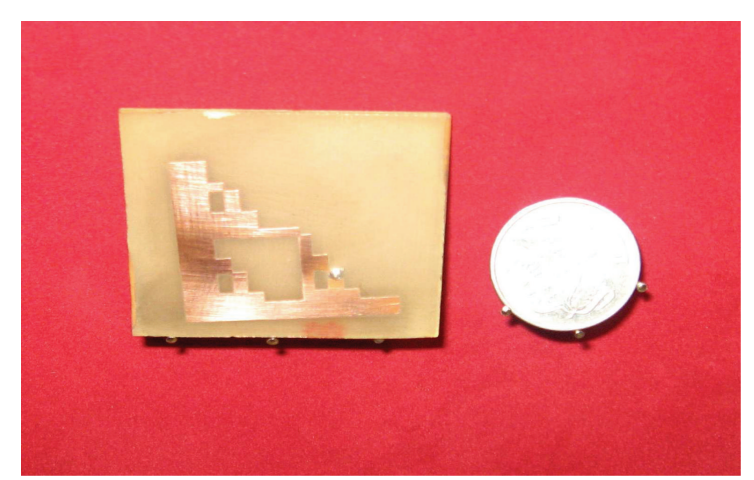

(e)

FIGURE 2: (a) Initiator (S1), (b) first iteration (S2), (c) second iteration (S3), (d) third iteration (S4), (e) prototype of the planar antenna (all dimensions are in $\mathrm{mm}$ ).

The performance of self-affine cantor which is obtained at $-10 \mathrm{~dB}$ references covers the nearby frequency bands. The antenna covers the neighboring frequency bands thereby providing a $S_{11}$ greater than $-20 \mathrm{~dB}$ for a feed position and multiband characteristics for all the other positions. As iteration $(n)$ increases, the slots grow at the centre and the staircase projections increase diagonally from to right reveling the affinity concept. Simulated $S_{11}$ covers and fulfills the GSM band, WLAN, IEEE 802.11, Bluetooth, WiMAX, PCS, DCS, and UMTS requirements.

2.3. Antenna Fabrication and Testing. The proposed cantor is etched on FR4 substrate whose specifications have been discussed in Section 2.2, with 8:1 ratio of ferric chloride and dilutes hydrochloric acid. The optimized antenna measures

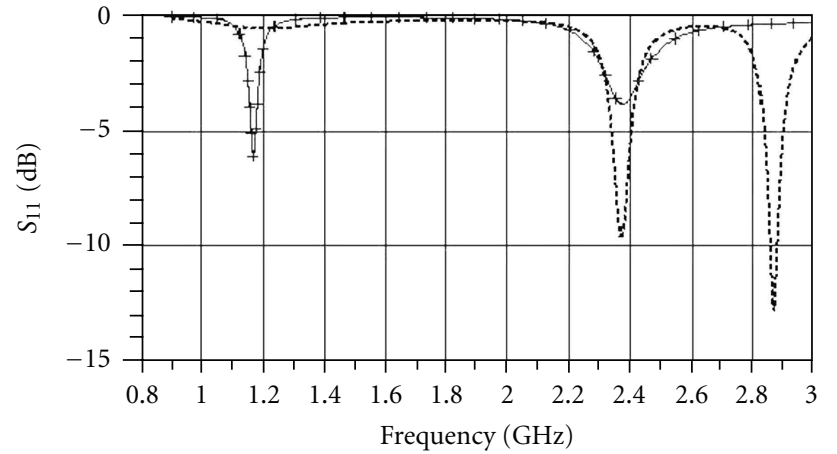

$$
\begin{aligned}
& \text {-... S2 }(21.34,8.15) \\
& --- \text { S2 }(21.26,7.7) \\
& \text { — S2 }(6.1,23.4)
\end{aligned}
$$

Figure 3: Comparison between different feed positions for second iteration (S3).

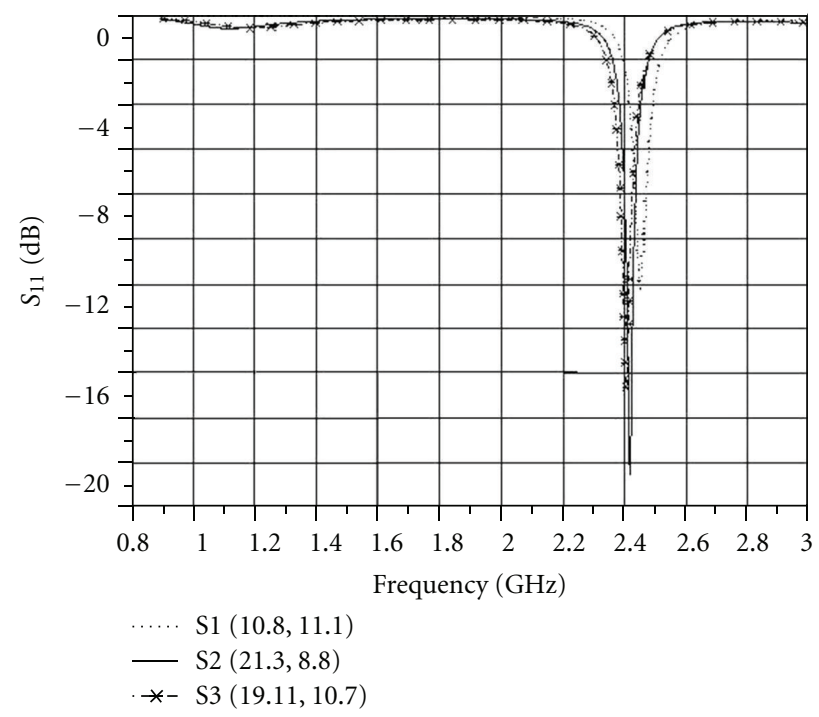

FIgURE 4: Performance comparison between initiator (S1), first iteration (S2), and second iteration (S3).

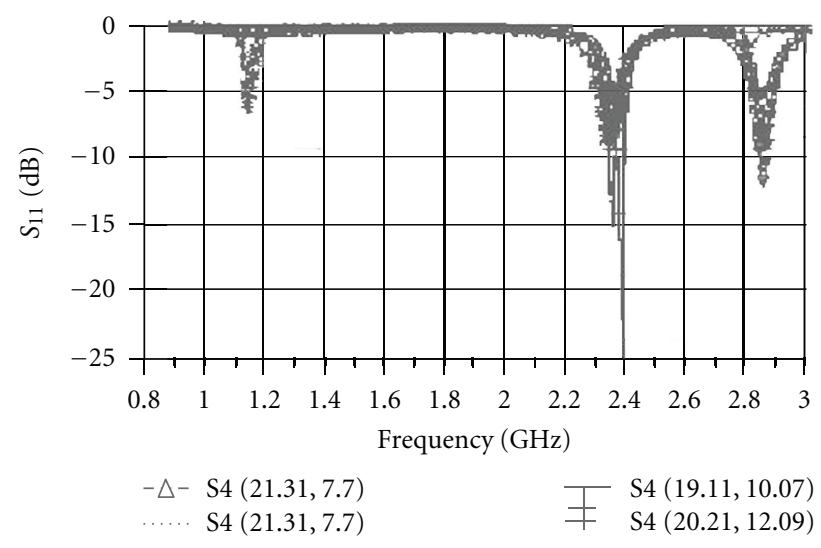

FIGURE 5: Comparison between different feed positions for third iteration (S4). 
TABLE 1: Simulated returnloss at various iterations for an self-affine antenna.

\begin{tabular}{|c|c|c|c|c|c|c|c|c|c|c|c|c|}
\hline \multirow[b]{2}{*}{ S. no } & \multicolumn{3}{|c|}{ S1 } & \multicolumn{3}{|c|}{ S2 } & \multicolumn{3}{|c|}{ S3 } & \multicolumn{3}{|c|}{$\mathrm{S} 4^{*}$} \\
\hline & $\begin{array}{c}\text { Freq } \\
(\mathrm{GHz})\end{array}$ & $\begin{array}{l}S_{11} \\
(\mathrm{~dB})\end{array}$ & $\begin{array}{c}\text { BW } \\
(\mathrm{MHz})\end{array}$ & $\begin{array}{c}\text { Freq } \\
(\mathrm{GHz})\end{array}$ & $\begin{array}{l}S_{11} \\
(\mathrm{~dB})\end{array}$ & $\begin{array}{c}\text { BW } \\
(\mathrm{MHz})\end{array}$ & $\begin{array}{c}\text { Freq } \\
(\mathrm{GHz})\end{array}$ & $\begin{array}{c}S_{11} \\
(\mathrm{~dB})\end{array}$ & $\begin{array}{c}\text { BW } \\
(\mathrm{MHz})\end{array}$ & $\begin{array}{c}\text { Freq } \\
(\mathrm{GHz})\end{array}$ & $\begin{array}{c}S_{11} \\
(\mathrm{~dB})\end{array}$ & $\begin{array}{c}\text { BW } \\
(\mathrm{MHz})\end{array}$ \\
\hline 1 & 2.425 & -12.29 & 19 & 2.419 & -17 & 26 & 1.167 & -6 & - & $2.369(1)$ & -9.575 & - \\
\hline 2 & & & & & & & 2.369 & -9.58 & - & $2.865(2)$ & -12.77 & 13 \\
\hline 3 & & & & & & & & & & $2.366(3)$ & -9.687 & - \\
\hline 4 & & & & & & & & & & $2.863(4)$ & -9.985 & - \\
\hline 5 & & & & & & & Feed po & tion wit & espect to* & $2.357(5)$ & -16.03 & 25 \\
\hline 6 & & & & & & & 21.311 & 7.7082 & and (2) & $2.841(5)$ & -6.198 & - \\
\hline 7 & & & & & & & 21.477 & 6.5875 & and (3) & $2.389(6)$ & -23.55 & - \\
\hline 8 & & & & & & & & $604,1.8$ & $9(5)$ & $2.378(7)$ & -24.55 & 26.1 \\
\hline 9 & & & & & & & 19.11 & 10.0742 & and (7) & $1.15(8)$ & -7.094 & - \\
\hline 10 & & & & & & & 6.10 & 23.4 & ind (9) & $2.34(9)$ & -9.375 & - \\
\hline
\end{tabular}

* 4 feed position.

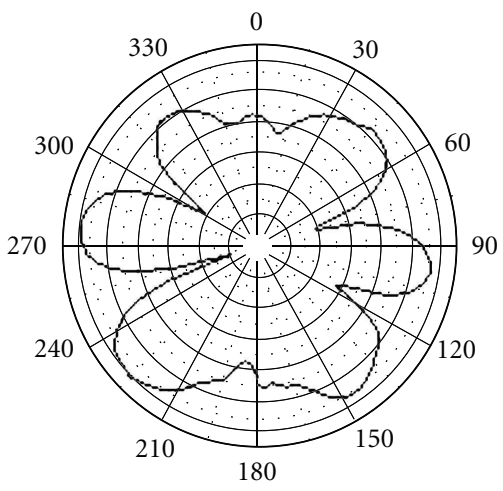

$1.95 \mathrm{GHz} E \theta$ plane

(a)

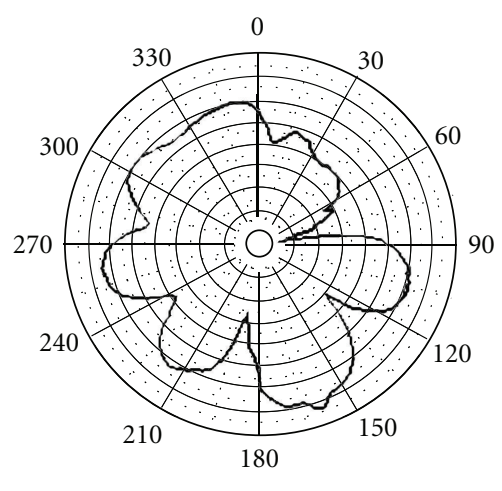

$1.95 \mathrm{GHz} E \varphi$ plane

(d)

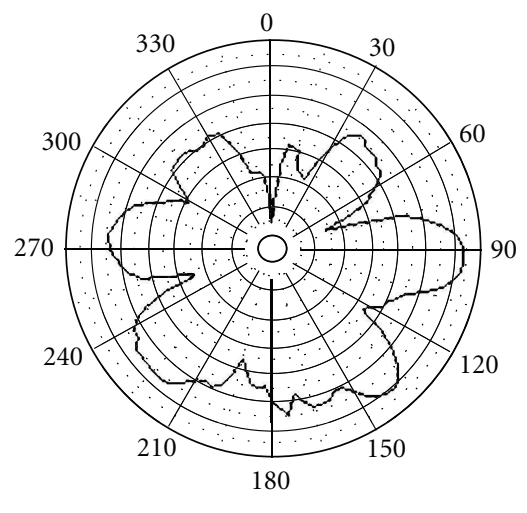

$2 \mathrm{GHz} E \theta$ plane

(b)

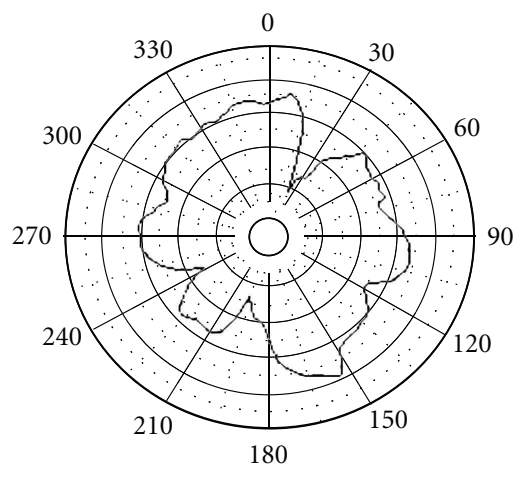

$2 \mathrm{GHz} E \varphi$ plane

(e)

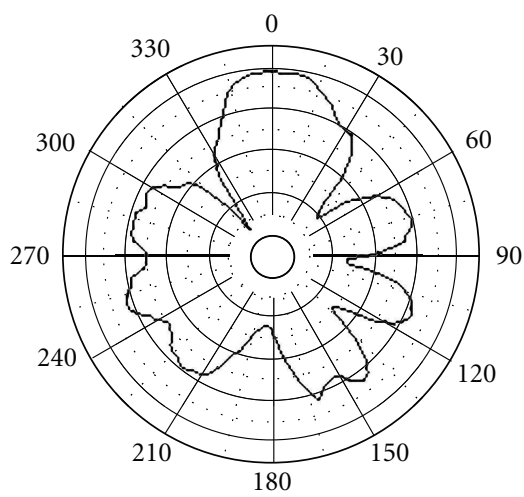

2.4 GHz $E \theta$ plane

(c)

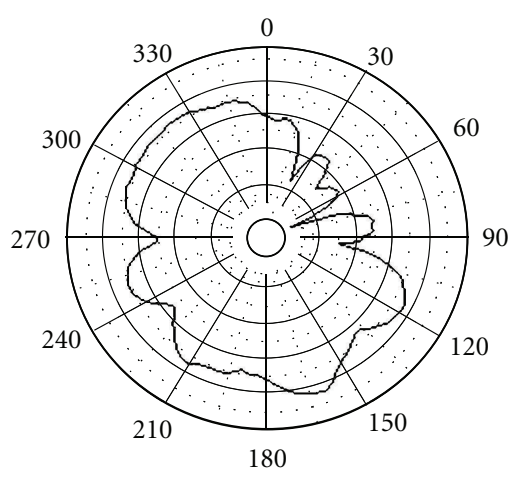

2.4 GHz $E \varphi$ plane

(f)

FIGURE 6: Measured radiation pattern for $E \theta$ and $E \varphi$ planes for $1.95 \mathrm{GHz}, 2 \mathrm{GHz}$, and $2.4 \mathrm{GHz}$.

$38.734 \mathrm{~mm} \times 28.757 \mathrm{~mm}$ as shown in Figure 2(e). Here, coaxial feed is considered at $21.56 \mathrm{~mm} \times 1.89 \mathrm{~mm}$. The radiation pattern is obtained in a anechoic chamber of $8 \mathrm{~m} \times$ $4 \mathrm{~m} \times 4 \mathrm{~m}(L \times W \times H)$ dimensions at $1.95 \mathrm{GHz}, 2 \mathrm{GHz}$ and $2.45 \mathrm{GHz}$, for $E \theta$ and $E \varphi$ planes against, standard gain of the pyramidal horn antenna $(450 \mathrm{MHz}-6 \mathrm{GHz})$ and Agilent PNA $5230 \mathrm{~A}$ vector network analyzer $(10 \mathrm{MHz}-6 \mathrm{GHz})$ is shown in Figure 6. The antenna pattern is omnidirectional with slight variations; this may be because of the surrounding reflections caused during measurements. The resonant 
TABLE 2: Measured $S_{11}$ for an self-affine fractal antenna.

\begin{tabular}{lcccc}
\hline S. no & $\begin{array}{c}\text { Centre freq in } \\
\text { GHz }\end{array}$ & $S_{11}(\mathrm{~dB})$ & BW in MHz & $\begin{array}{c}\text { Combined } \\
\text { BW in MHz }\end{array}$ \\
\hline 1 & 0.963 & -22.15 & 105 & 147 \\
2 & 1.047 & -28.2 & 147 & \\
3 & 1.247 & -14.46 & 74 & \\
4 & 1.394 & -17.92 & 116 & \\
5 & 1.593 & -24.76 & 116 & \\
6 & 1.928 & -21.75 & 221 & \\
7 & 2.213 & -26.26 & 76 & \\
8 & 2.40 & -30.69 & 186 & \\
9 & 2.811 & -30.63 & 189 & \\
\hline
\end{tabular}

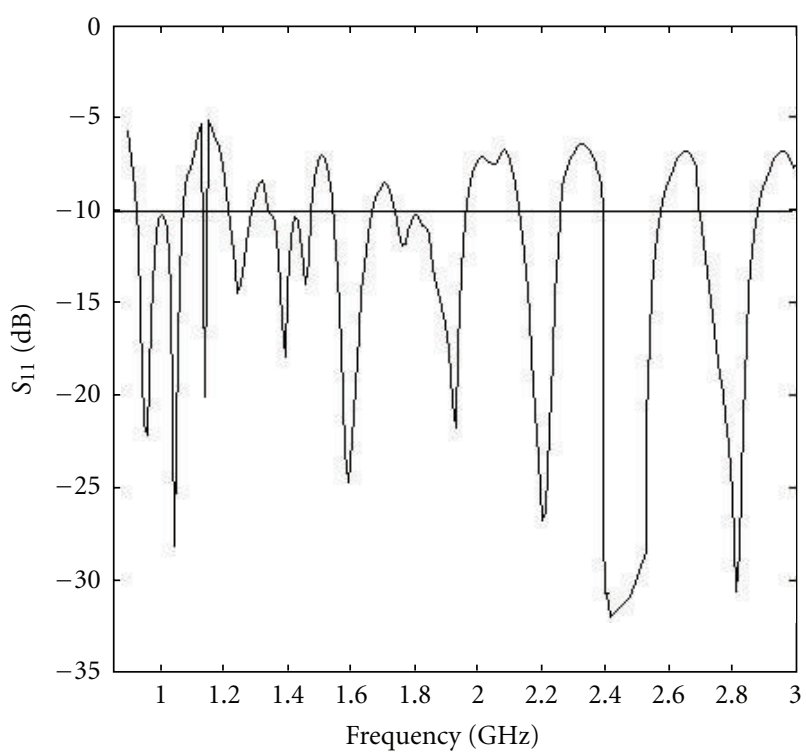

FIgURE 7: Measured $S_{11}$ of self-affine fractal antenna structure.

behavior of the proposed antenna is measured using Agilent network analyzer with $-10 \mathrm{~dB}$ as references is obtained and the corresponding values are tabulated in Table 2. The simulated and measured $S_{11}$ gives a good agreement as shown in Figure 7. The performance of the antenna is compared against earlier published self-affine fractal antenna as depicted in Figure 8. The antenna designed for $2.4 \mathrm{GHz}$ resonates for $0.9 \mathrm{GHz}, 1.075 \mathrm{GHz}, 1.25 \mathrm{GHz}$, and $1.95 \mathrm{GHz}$ with $11.5931 \mathrm{dBi}, 9.43717 \mathrm{dBi}, 8.25 \mathrm{dBi}$, and $3.69 \mathrm{dBi}$ gain in that order. The self-affine fractal cantor provides multi-band characteristics at $2.402 \mathrm{GHz}$ with a $S_{11}$ parameter $-30.69 \mathrm{~dB}$.

\section{Conclusion}

A compact multiband low profile planar antenna designed at 2.4 GHz exhibiting multiband characteristics which crowns WLAN IEEE 802.11b and IEEE802.15, PCS, GSM lowerband, GSM higher band, DCS, IMT, UMTS, Wi-Fi, and WLAN wireless applications. The compact multiband selfaffine antenna maintains a $S_{11}$ of -30.69 at design frequency. The gain of the antenna is simulated at $0.9 \mathrm{GHz}, 1.075 \mathrm{GHz}$,

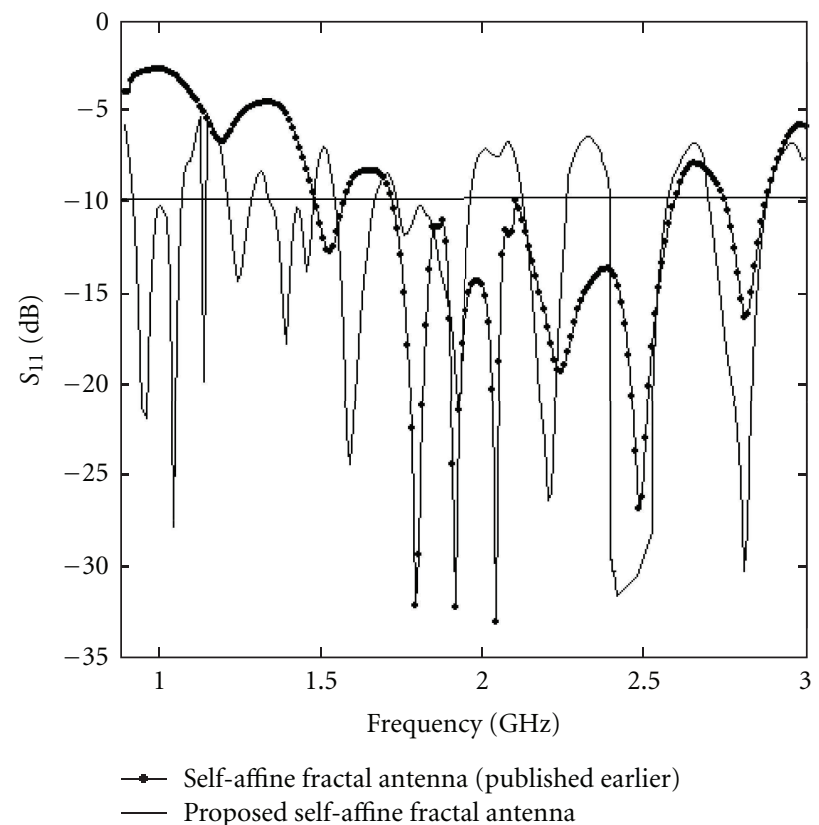

FIGURE 8: Performance comparisons of measured $S_{11}$ parameter between self-affine fractal antennas.

and $1.25 \mathrm{GHz}$ with a gain of $11.5931 \mathrm{dBi},-9.43717 \mathrm{dBi}$, and $8.25 \mathrm{dBi}$, respectively. At design frequency the $E \theta$ and $E \varphi$ planes have gain $4.46 \mathrm{dBi}$ and $7.17 \mathrm{dBi}$, respectively. The authors have chosen a FR4 substrate which is low in cost and lossy in nature, approximately $30 \%$ of the wave form is above the reference level and this might be due to the imperfect finishing caused by fabrication.

\section{Acknowledgment}

This work was supported by Agilent-Multipurpose Lab Station, PSG College of Technology, Coimbatore India.

\section{References}

[1] Y.-B. Kwon, J.-I. Moon, and S.-O. Park, "An internal tripleband planar inverted-F antenna," IEEE Antennas and Wireless Propagation Letters, vol. 2, pp. 341-344, 2003.

[2] M.-C. Huynh and W. L. Stutzman, "A low-profile compact multi-resonant antenna for wideband and multi-band personal wireless applications," in Proceedings of the IEEE Antennas and Propagation Society Symposium Digest Held in Conjunction with: USNC/URSI National Radio Science Meeting, vol. 2, pp. 1879-1882, June 2004.

[3] D. U. Sim, J.-I. Moon, and S.-O. Park, "An internal tripleband antenna for PCS/IMT-2000/bluetooth applications," IEEE Antennas and Wireless Propagation Letters, vol. 3, no. 1, pp. 23-25, 2004.

[4] D. U. Sim, J.-I. Moon, and S.-O. Park, "A wideband monopole antenna for PCS/IMT-2000/Bluetooth applications," IEEE Antennas and Wireless Propagation Letters, vol. 3, no. 1, pp. 4547, 2004.

[5] Y. S. Shin, S.-O. Park, and M. Lee, "A broadband interior antenna of planar monopole type in handsets," IEEE Antennas and Wireless Propagation Letters, vol. 4, no. 1, pp. 9-12, 2005. 
[6] Y. S. Cao, C. L. Lu, and Y. L. Zhang, "A compact dual band miniaturized antenna for WLAN operation," in Proceedings of the International Conference on Microwave and Millimeter Wave Technology (ICMMT '08), pp. 416-419, April 2008.

[7] Q. Q. He, B. Z. Wang, and J. He, "Wideband and dualband design of a printed dipole antenna," IEEE Antennas and Wireless Propagation Letters, vol. 7, pp. 1-4, 2008.

[8] R. L. Li, B. Pan, J. Laskar, and M. M. Tentzeris, "A novel lowprofile broadband dual-frequency planar antenna for wireless handsets," IEEE Transactions on Antennas and Propagation, vol. 56, no. 4, pp. 1155-1162, 2008.

[9] M. N. Suma, R. K. Raj, M. Joseph, P. C. Bybi, and P. Mohanan, "A compact dual band planar branched monopole antenna for DCS/2.4-GHz WLAN applications," IEEE Microwave and Wireless Components Letters, vol. 16, no. 5, pp. 275-277, 2006.

[10] M. J. Kim, C. S. Cho, and J. Kim, "A dual band printed dipole antenna with spiral structure for WLAN application," IEEE Microwave and Wireless Components Letters, vol. 15, no. 12, pp. 910-912, 2005.

[11] M. F. Barnsley, Fractals Everywhere, Academic Press, San Diego, Calif, USA, 2nd edition, 1993.

[12] H. O. Peitgen, H. Jurgens, and D. Saupe, Chaos and Fractals, NewFrontiers in Science, Springer, NewYork, NY, USA, 1992.

[13] C. Puente, J. Romeu, R. Pous, X. Garcia, and F. Benitez, "Fractal multiband antenna based on the Sierpinski gasket," Electronics Letters, vol. 32, no. 1, pp. 1-2, 1996.

[14] J. P. Gianvittorio and Y. Rahmat-Samii, "Fractal antennas: a novel antenna miniaturization technique, and applications," IEEE Antennas and Propagation Magazine, vol. 44, no. 1, pp. 20-36, 2002.

[15] D. H. Werner and S. Ganguly, "An overview of fractal antenna engineering research," IEEE Antennas and Propagation Magazine, vol. 45, no. 1, pp. 38-57, 2003.

[16] K. J. Vinoy, Fractals shaped antenna elements for wide band multiband wireless applications [Ph.D. thesis], Department of Electrical Engineering, Pennslavania State University, University Park, Pa, USA, 2002.

[17] J. C. Liu, C. Y. Wu, D. C. Chang, and C. Y. Liu, "Relationship between sierpenski and appolian packing monopole antennas," Electronics Letters, vol. 42, no. 15, 2006.

[18] T. K. C. Lo and Y. Hwang, "Microstrip antennas of very high permittivity for personal communications," in Proceedings of the Asia-Pacific Microwave Conference (APMC '97), pp. 253256, December 1997.

[19] R. A. Sainati, CAD of Microstrip Antennas For Wireless Applications, Artech House, Norwood, NJ, USA, 1996.

[20] H. Y. Wang and M. J. Lancaster, "Aperture-coupled thin-film superconducting meander antennas," IEEE Transactions on Antennas and Propagation, vol. 47, no. 5, pp. 829-836, 1999.

[21] P. E. Mayes, "Frequency-independent antennas and broadband derivatives thereof," Proceedings of the IEEE, vol. 80, no. 1, pp. 103-112, 1992.

[22] C. Puente-Baliarda, J. Romeu, R. Pous, and A. Cardama, "On the behavior of the sierpinski multiband fractal antenna," IEEE Transactions on Antennas and Propagation, vol. 46, no. 4, pp. 517-524, 1998.

[23] I. K. Kim, J. G. Yook, and H. K. Park, "Fractal-shape small size microstrip patch antenna," Microwave and Optical Technology Letters, vol. 34, no. 1, pp. 15-17, 2002.

[24] S. N. Sinha and M. Jain, "A self-affine fractal multiband antenna," IEEE Antennas and Wireless Propagation Letters, vol. 6, pp. 110-112, 2007.

[25] X. He, S. Hong, H. Xiong, Q. Zhang, and E. M. M. Tentzeris, "Design of a novel high-gain dual-band antenna for WLAN applications," IEEE Antennas and Wireless Propagation Letters, vol. 8, pp. 798-801, 2009.

[26] W.-C. Liu, M. Ghavami, and W.-C. Chung, "Triple-frequency meandered monopole antenna with shorted parasitic strips for wireless application," IET Microwaves, Antennas and Propagation, vol. 3, no. 7, pp. 1110-1117, 2009.

[27] R. Li, B. Pan, J. Laskar, and M. M. Tentzeris, "A compact broadband planar antenna for GPS, DCS-1800, IMT-2000, and WLAN applications," IEEE Antennas and Wireless Propagation Letters, vol. 6, pp. 25-27, 2007.

[28] R. Azaro, L. Debiasi, E. Zeni, M. Benedetti, P. Rocca, and A. Massa, "A hybrid prefractal three-band antenna for multistandard mobile wireless applications," IEEE Antennas and Wireless Propagation Letters, 2009.

[29] M. N. Suma, R. K. Raj, M. Joseph, P. C. Bybi, and P. Mohanan, "A compact dual band planar branched monopole antenna for DCS/2.4-GHz WLAN applications," IEEE Microwave and Wireless Components Letters, vol. 16, no. 5, pp. 275-277, 2006. 

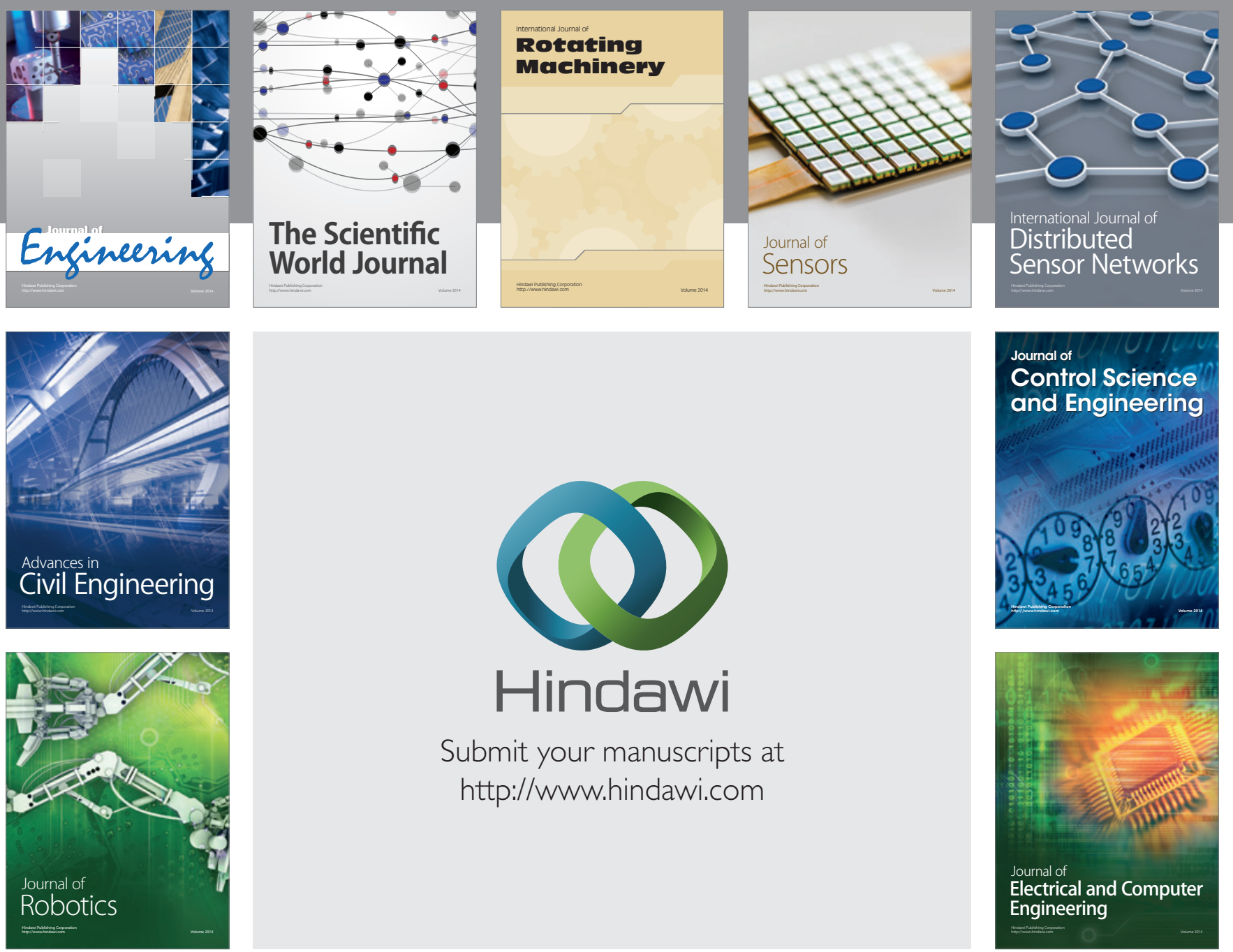

Submit your manuscripts at

http://www.hindawi.com
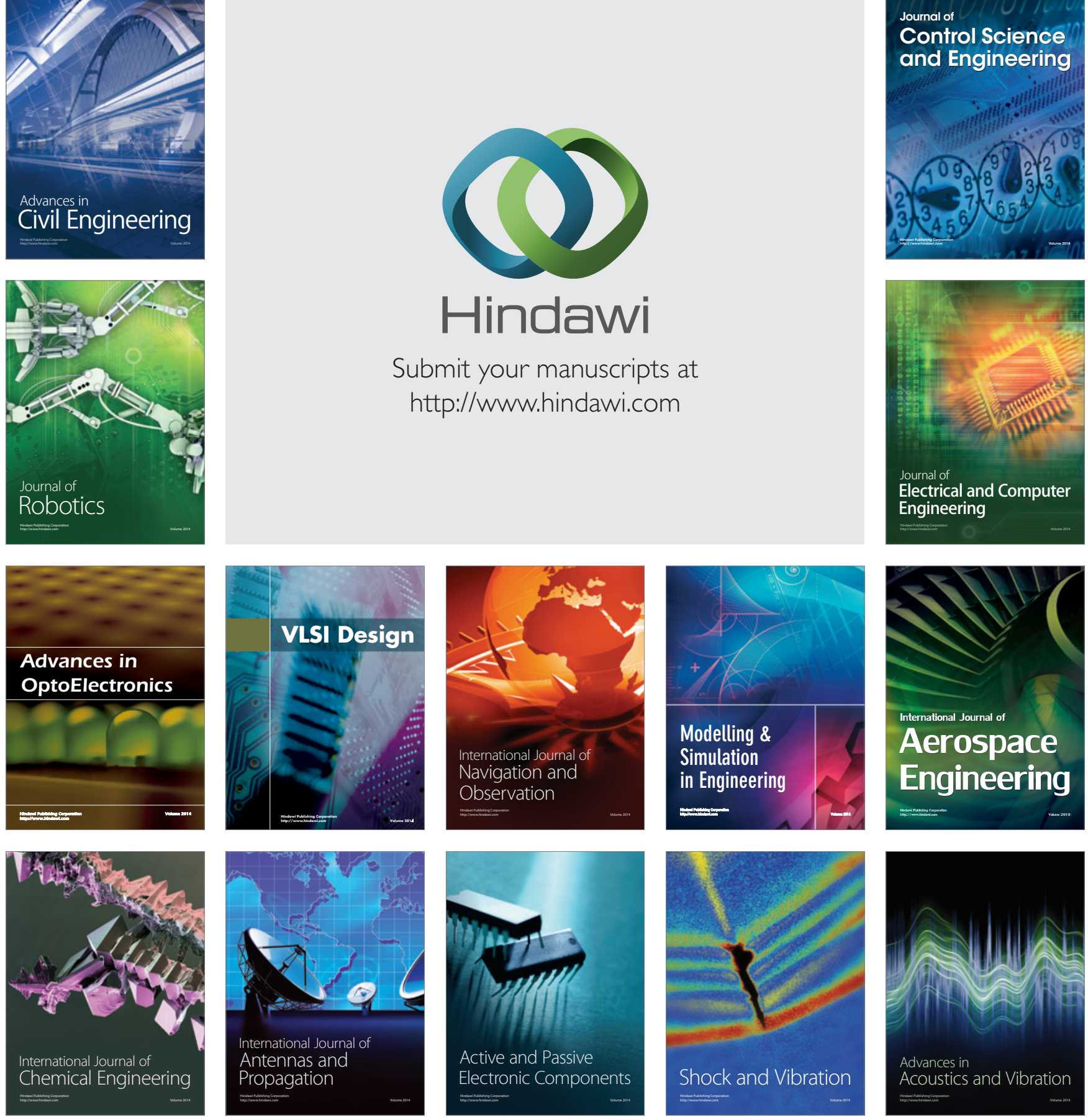